\title{
Effects of a second insemination after ovulation on fertilization rate and accessory sperm count in sows
}

\author{
N. M. Soede, C. C. H. Wetzels, W. Zondag, W. Hazeleger and \\ B. Kemp \\ Department of Animal Husbandry, Marijkeweg 40,6709 PG Wageningen Agricultural University, \\ Wageningen, The Netherlands
}

\begin{abstract}
Insemination immediately after ovulation causes low fertilization results owing to a low fertilization rate and possibly also owing to polyspermic fertilization. The present experiment was undertaken to study the effects of a second insemination after ovulation on fertilization rate and embryonic development. In multiparous crossbred sows, transrectal ultrasonography was used at intervals of $4 \mathrm{~h}$ to determine ovulation. All sows $(n=91)$ were artificially inseminated with $3 \times 10^{9}$ mixed spermatozoa and, in 31 sows, a second insemination took place at $3 \pm 1$ (mean $\pm \mathrm{SD}$ ) $\mathrm{h}$ after ovulation. At $119 \pm 5 \mathrm{~h}$ after ovulation, the percentage of normal embryos and the accessory sperm count were determined. In the sows that were inseminated once, the percentage of normal embryos decreased when insemination took place more than $24 \mathrm{~h}$ before ovulation, from $88 \pm 20 \%(16-24 \mathrm{~h} ; n=15)$ to $63 \pm 40 \%$ $(24-32 \mathrm{~h} ; n=10)(P<0.05)$. In the sows that were inseminated again after ovulation, the percentage of normal embryos was high, irrespective of the period between first insemination and ovulation. The difference in percentage of normal embryos between the sows that were inseminated once or twice was significant when the first insemination took place between 24 and $32 \mathrm{~h}$ before ovulation; $63 \pm 40 \%$ (inseminated once, $n=10$ ) and $97 \pm 5 \%$ (inseminated twice, $n=8)(P<0.05)$. The accessory sperm count of the normal embryos in a litter was positively related to the percentage of normal embryos in a litter, and this relation was not affected by the interval between first insemination and ovulation or by the number of inseminations. On the basis of the high percentage of normal embryos in sows that were inseminated twice and the positive relation between the accessory sperm count and the percentage of normal embryos, it is concluded that under these experimental conditions, fertilization results were affected positively by a second insemination after ovulation.
\end{abstract}

\section{Introduction}

When insemination takes place after ovulation, fertilization results are often poor (Hunter, 1967a; Waberski et al., 1994; Soede et al., 1995). It is assumed that the decrease in fertilization rate is caused by the limited lifespan of the oocytes, in combination with the time needed for sperm cells to capacitate and reach the site of fertilization (Hunter, 1994). Recent studies of oocytes and embryos from postovulatory insemination showed that the fertilized oocytes often contain large numbers of spermatozoa (the accessory sperm cells) in the zona pellucida (Waberski et al., 1994; Soede et al., 1995). This corresponds to the findings of Hunter (1984, 1994) that, after ovulation, the regulation of the number of spermatozoa passing from the uterus to the site of fertilization is less effective, increasing the chance that oocytes are confronted by two or more competent spermatozoa simultaneously, increasing the rate of polyspermic fertilization (Hunter, 1973).

In pig husbandry, many sows are inseminated twice or even more, with an interval between two subsequent inseminations or matings of $12-24 \mathrm{~h}$. A greater number of inseminations

Received 18 April 1995. increases the chance of postovulatory insemination. A decrease in fertilization rate might be expected in sows in which a second insemination takes place after ovulation, on the basis of the assumption that this second insemination increases the number of spermatozoa at the site of fertilization and consequently increases the chances of polyspermic fertilization.

An experiment was performed to study the possible negative effects of a second insemination shortly after ovulation on fertilization. Within each $8 \mathrm{~h}$ period of (first) insemination to ovulation, half of the sows were inseminated again shortly after ovulation. Ovulation was checked with transrectal ultrasonography and fertilization results were judged in prehatched embryos, which allows for assessment of fertilization rate, the percentage of normal and degenerating embryos and the number of accessory sperm cells.

\section{Materials and Methods}

Animals and housing

For a period of 4 months, every 2 weeks ( 8 rounds), 11-15 sows (103 in total) were obtained at the day of weaning. After 
arrival at the experimental farm, the sows were housed individually and received approximately $2.5 \mathrm{~kg}$ of commercial sow diet (12.9 $\mathrm{MJ} \mathrm{ME} \mathrm{kg}^{-1}$ ) daily and water ad libitum. Only healthy sows that ovulated between day 3 and day 8 after weaning $(n=91)$ were used. The number of sows from parity 2 to 5 was $42,30,28$ and 3 , respectively. The sows were from three synthetic lines (A, $n=40 ; B, n=27$, and; C, $n=24$ ), which were parent lines for commercial crossbred sows and boars (Dalland b.v., Merselo).

\section{Detection of oestrus}

Detection of oestrus was performed at intervals of $8 \mathrm{~h}$, from approximately $62 \mathrm{~h}$ after weaning until the end of oestrus. The boar was taken to the sows and the back pressure test was performed in the presence of the boar. The time of onset of oestrus was defined as the first time a sow showed a standing response minus $4 \mathrm{~h}$. The time of end of oestrus was defined as the last time the sow showed a standing response plus $4 \mathrm{~h}$.

\section{Detection of ovulation}

At approximately $70 \mathrm{~h}$ after weaning, transrectal ultrasonography was performed to check the presence and size of follicles on corpora lutea on the ovaries. From $16 \mathrm{~h}$ after the onset of oestrus, transrectal ultrasonography was performed at intervals of $4 \mathrm{~h}$ to assess the moment of ovulation. An annular array sector scanner (type 150V, Pie Medical b.V., Maastricht) with a 5-7.5 MHz multiple scan angle transducer was used. During scanning, the presence or absence of preovulatory follicles (diameter of antrum $>4 \mathrm{~mm}$ ) was determined. Time of ovulation was defined as the first time of zero follicle count minus $2 \mathrm{~h}$. When the follicle count was not zero, but noticeably lower than before, ovulation was assumed to have just started $(t=0)$, since ovulation takes on average $2 \mathrm{~h}$ in spontaneously ovulating sows (Soede et al., 1992). Ovulation was confirmed by one additional scanning $4 \mathrm{~h}$ later. Frequent scanning around ovulation has no apparent effect on fertilization (Soede and Kemp, 1993).

\section{Insemination}

At variable periods from the onset of oestrus, sows were taken to the boar pen and artificially inseminated once with a commercial dose of $3 \times 10^{9}$ mixed spermatozoa in the presence of the boar. Half of the sows were inseminated for a second time at $3 \pm 1(0-5) \mathrm{h}$ after ovulation. This second insemination took place in the sow pen in the absence of a boar. The age of spermatozoa at first insemination was $28 \pm 7(18-35) \mathrm{h}$ and age at second insemination was $29 \pm 7(19-40) \mathrm{h}$. At the Artificial Insemination Centre, sperm quality was assessed for 3 consecutive days in samples of the spermatozoa using a microscope (magnification $\times 200$ ). At day 0 , the percentage of motile spermatozoa varied from $70 \%$ to $80 \%$ (assessed in steps of $10 \%)$, and the quality of motility varied from 6 to $7(0=$ very bad; $10=$ very good). After 2 days, these quality parameters varied from $60 \%$ to $80 \%$ and from 6 to 7 , respectively.

\section{Embryonic development}

Sows were slaughtered at $119 \pm 6(109-130) \mathrm{h}$ after ovulation. The number of corpora lutea was counted on both ovaries. Each oviduct was flushed with $15 \mathrm{ml}$ Dulbecco's PBS from the infundibulum into the uterus. Thereafter, the oviduct was separated from the uterus and each uterine horn was flushed twice with $30 \mathrm{ml}$ PBS to collect the embryos and oocytes. The recovery rate was determined as the percentage of embryos and oocytes recovered based on the number of corpora lutea. The quality and morphology of the recovered embryos and oocytes were assessed (magnification $\times 60$ ). Thereafter, they were subjected to hypotonic treatment $(0.6 \%$ $(\mathrm{w} / \mathrm{v}) \mathrm{KCl}, 0^{\circ} \mathrm{C}, 10 \mathrm{~min}$ ) and subsequently placed on a fat-free glass slide. Small droplets of methanol/acetic acid (3/1 v/v) were added until the disruption and spreading of the embryo (generally $1 \mathrm{~cm}^{2}$ ) to allow the nuclei and sperm cells to be counted (magnification $\times 200$ ) after drying and staining with $10 \%$ Giemsa in PBS solution. A nuclei count of zero or one was considered an unfertilized oocyte. Embryos with a degenerated morphology and a low number of nuclei were considered degenerated, others were considered normal embryos. The fertilization rate and the rate of normal and degenerating embryos were determined based on the total number of recovered embryos and oocytes.

\section{Statistical analyses}

Data were analysed using SAS (1990). The procedure GLM was used to analyse the effects of the $8 \mathrm{~h}$ classes of insemination-ovulation interval ( $\mathrm{I}-\mathrm{O}$ interval) and the effects of a second insemination after ovulation within these $8 \mathrm{~h}$ classes of $\mathrm{I}-\mathrm{O}$ intervals on embryo status (unfertilized, degenerated and normal embryos per litter) after arcsine transformation of the proportions of unfertilized, degenerate and normal embryos (Snedecor and Cochran, 1989). On the basis of percentage of normal embryos, the sows were divided into sows with $>90 \%$ normal embryos ('good' sows) and sows with $\leqslant 90 \%$ normal embryos ('bad' sows). This division was chosen based on the frequency distribution of the percentage of normal embryos per litter, which was: $0 \%(n=5)$, $>0-10 \%(n=0),>10-20 \%(n=1),>20-30 \%(n=1),>30-$ $40 \%(n=1),>40-50 \%(n=3),>50-60 \%(n=1),>60-70 \%$ $(n=2), \quad>70-80 \% \quad(n=2),>80-90 \% \quad(n=7), \quad>90-100 \%$ $(n=18), 100 \%(n=50)$, as has been done before (Soede et al., 1995). The division at $90 \%$ ensures that 'good' sows have at most two abnormal embryos. Differences in the accessory sperm count of the normal embryos per sow between the $\mathrm{I}-\mathrm{O}$ intervals of $8 \mathrm{~h}$, and between one and two inseminations within these $8 \mathrm{~h}$ classes of $\mathrm{I}-\mathrm{O}$ intervals, were analysed using the Wilcoxon test of the NPARIWAY procedure. Differences between the I-O classes of $8 \mathrm{~h}$ in embryo development of the normal embryos were analysed with GLM, using embryonic age as a covariable. Embryo development was expressed as the average number of cell cycles $\left({ }^{2} \log (\right.$ nuclei count)) per litter. Embryonic age was defined as the time (h) between ovulation and slaughter for sows that were inseminated before ovulation. For sows that were inseminated at or after ovulation, embryonic age was defined as the time ( $h$ ) between insemination and slaughter. Embryonic age, thus defined, neither takes into 
Table 1. The percentage of normal developed embryos at $119 \pm 5 \mathrm{~h}$ after ovulation, in sows inseminated once or twice, related to the interval between first insemination and ovulation $(n=19)$

\begin{tabular}{|c|c|c|c|c|c|c|}
\hline \multirow{2}{*}{$\begin{array}{l}\text { Interval between } \\
\text { first insemination } \\
\text { and ovulation (h) }\end{array}$} & \multicolumn{3}{|c|}{ One insemination } & \multicolumn{3}{|c|}{ Two inseminations ${ }^{\top}$} \\
\hline & $n$ & $\begin{array}{c}\text { Mean }^{2} \\
\text { Median (range) }\end{array}$ & $>90 \%{ }^{3}$ & $n$ & $\begin{array}{c}\text { Mean }^{2} \\
\text { Median (range) }\end{array}$ & $>90 \%{ }^{3}$ \\
\hline \multicolumn{7}{|c|}{ First insemination before ovulation (h) } \\
\hline$\geq 32$ & 5 & $0_{0}^{64^{a}}(0-100)$ & 40 & 0 & - & 一 \\
\hline$<32-\geq 24$ & 10 & $87^{81^{\mathrm{ac}}}(0-100)$ & 40 & 8 & $\begin{array}{c}98^{\mathrm{b}} \\
100(87-100)\end{array}$ & 88 \\
\hline$<24-\geq 16$ & 15 & $\begin{array}{ll}96^{b} \\
100 \quad(40-100)\end{array}$ & 73 & 8 & $\begin{array}{c}97^{\mathrm{b}} \\
95(78-100)\end{array}$ & 63 \\
\hline$<16-\geq 8$ & II & $100 \quad \begin{array}{l}96^{\mathrm{b}} \\
(0-100)\end{array}$ & 91 & 12 & $\begin{array}{c}99^{b} \\
100(91-100)\end{array}$ & 100 \\
\hline$<8-\geq 0$ & 4 & $\begin{array}{c}99^{\mathrm{b}} \\
100(100-100)\end{array}$ & 100 & 3 & $\begin{array}{c}94^{\mathrm{bc}} \\
93(69-95)\end{array}$ & 67 \\
\hline \multicolumn{7}{|c|}{ First insemination after ovulation (h) } \\
\hline & & $100 \quad(33-100)$ & & & & \\
\hline
\end{tabular}

${ }^{1} T$ The second insemination took place at $3 \pm 1(0-5) \mathrm{h}$ after ovulation.

${ }^{2}$ Retransformed values of the mean of the arcsine transformed values (skewness $=-1.0$, kurtosis $=2.9$ ).

. Percentage of sows with more than $90 \%$ normal developed embryos.

Values with different letters are significantly different $(P<0.05)$.

account the time it takes gametes to reach the site of fertilization (oocytes and sperm cells, respectively) nor the time it takes for all oocytes to be penetrated. In gilts inseminated at the expected moment of ovulation (500 i.u. hCG), Hunter and Dziuk (1968) found accessory sperm cells in oocytes within $2 \mathrm{~h}$ after insemination. This finding indicates that both oocyte and sperm transport may take less than $2 \mathrm{~h}$. Therefore, although embryonic age does not start at exactly the time of ovulation or insemination, the difference is considered to be not more than a few hours. All values are expressed as means $\pm \mathrm{sD}$ (range).

\section{Results}

\section{Animals}

Of the 103 sows obtained, 12 were not used for the experiment; two showed lactational oestrus (corpora lutea at day 3), three were in oestrus at first detection, two ovulated within $16 \mathrm{~h}$ from the onset of oestrus, one had cystic ovaries at day 8, two were lame and two had an infection of the intestines. Therefore, 91 sows were used for the experiment.

\section{Oestrus and ovulation}

In the 91 sows, the mean weaning to oestrus interval was $87 \pm 15(66-130) \mathrm{h}$. The mean duration of oestrus was $60 \pm 11$ $(32-88) \mathrm{h}$ and ovulation took place $41 \pm 8(22-58) \mathrm{h}$ after onset of oestrus. These parameters were similar $(P>0.10)$ for the two treatments. After correction for the duration of oestrus $(P<0.001)$, the time from ovulation to the end of oestrus differed between the sows that were inseminated once and twice; $18.8 \pm 0.6$ and $21.6 \pm 0.8$ (LSM $\pm \mathrm{SEM}, P<0.01$, respectively). Consequently, ovulation took place at different relative times during oestrus, at $69 \pm 1$ and $64 \pm 1 \%$ (LSM \pm SEM, $P<0.001$ ), for sows inseminated once and twice, respectively.

\section{Embryo recovery and embryo status}

The mean number of corpora lutea was $21 \pm 4(12-36)$ and the recovery rate of embryos and oocytes was $88 \pm 9$ (48$100) \%$. The percentage of degenerating embryos per sow varied from $0 \%$ to $39 \%$ and was not related to the interval between insemination and ovulation, and did not differ between the sows that were inseminated either once or twice $(P>0.10)$. The percentage of normal embryos (of the recovered oocytes and embryos) is presented per $\mathrm{I}-\mathrm{O}$ interval of $8 \mathrm{~h}$ (Table 1), for the sows that were inseminated once and twice, respectively. Five of the 91 sows had $0 \%$ good embryos (these were all sows that were inseminated once); one of 11 sows inseminated between 8 and $16 \mathrm{~h}$ before ovulation, one of ten sows inseminated between 24 and $32 \mathrm{~h}$ before ovulation and three of five sows inseminated between 32 and $40 \mathrm{~h}$ before ovulation. Of the sows inseminated once, the percentage of normal developed embryos tended to decline when insemination took place more than $24 \mathrm{~h}$ before ovulation $(P<0.10)$.

Sows inseminated for a second time after ovulation had good fertilization results, independent of the interval from first insemination to ovulation. A second insemination resulted in a higher percentage of normal embryos when the first insemination took place more than $24 \mathrm{~h}$ before ovulation $(97 \pm 5$ $(87-100)$ versus $63 \pm 40(0-100) ; P<0.05)$. Similarly, the percentage of sows with at least $90 \%$ normal embryos increased from $40 \%$ (four of ten sows) to $88 \%$ (seven of eight sows) with two inseminations. 
Table 2. The accessory sperm count of normal developed embryos at $119 \pm 5 \mathrm{~h}$ after ovulation, in sows inseminated once or twice, related to the interval between first insemination and ovulation $(n=86)$

\begin{tabular}{|c|c|c|c|c|c|c|}
\hline \multirow{2}{*}{$\begin{array}{l}\text { Interval between } \\
\text { first insemination } \\
\text { and ovulation (h) }\end{array}$} & \multicolumn{3}{|c|}{ One insemination } & \multicolumn{3}{|c|}{ Two inseminations ${ }^{1}$} \\
\hline & $n$ & Median & Range & $n$ & Median & Range \\
\hline \multicolumn{7}{|c|}{ First insemination before ovulation (h) } \\
\hline$\geq 32$ & 2 & $4^{\mathrm{bc}}$ & $3-4$ & 0 & - & - \\
\hline$<32-\geq 24$ & 9 & $1^{b x}$ & $0-3$ & 8 & $100^{y}$ & $17-202$ \\
\hline$<24-\geq 16$ & 15 & $7^{\mathrm{bx}}$ & $0-51$ & 8 & $89^{y}$ & $32-165$ \\
\hline$<16-\geq 8$ & 10 & $22^{\mathrm{bcx}}$ & $3-62$ & 12 & $100^{y}$ & $25-293$ \\
\hline$<8-\geq 0$ & 4 & $71^{\text {ac }}$ & $5-104$ & 3 & 230 & $10-235$ \\
\hline \multicolumn{7}{|c|}{ First insemination after ovulation (h) } \\
\hline$<0-\geq-8$ & 15 & $93^{\mathrm{a}}$ & $0-210$ & 0 & - & - \\
\hline
\end{tabular}

\footnotetext{
${ }^{1}$ The second insemination took place at $3 \pm 1(0-5) \mathrm{h}$ after ovulation.

${ }^{\mathrm{abc}}$ Values with different letters within a column are significantly different $(P<0.05)$

${ }^{x y}$ Values with different letters within a row are significantly different $(P<0.05)$.
}

Embryo development in terms of the mean number of cell cycles of the normal embryos in a litter was $5.5 \pm 0.6(2.8-6.8)$. Embryo development corrected for embryo age was not affected by the interval between first insemination and ovulation, nor by the number of inseminations. The number of cell cycles was related to the age of the embryos as follows: cell cycles $=0.045 \times$ age $+0.17\left(R^{2}=0.17, P<0.001, n=86\right.$; only sows with at least one normal embryo). The number of residual cell cycles after correction for age was related to the percentage of normal embryos per litter as follows: residual cell cycles $=0.015 \times \%$ normal $-1.34\left(R^{2}=0.22, P<0.001, n=86\right)$.

\section{Accessory sperm count}

The mean accessory sperm count of the normal embryos per litter varied between 0 and 293 and the median was 32 (86 litters). Of the degenerating embryos and unfertilized oocytes, the median accessory sperm count was $17(0-366 ; 25$ litters $)$ and $0.5(0-165 ; 27$ litters), respectively. The sperm count of degenerating embryos and unfertilized oocytes was not affected by the $\mathrm{I}-\mathrm{O}$ interval or the number of inseminations $(P>0.10)$. The accessory sperm count of the normal embryos is presented per $\mathrm{I}-\mathrm{O}$ interval of $8 \mathrm{~h}$ (Table 2), for the sows that were inseminated once and twice, respectively. In sows that were inseminated once, the accessory sperm count decreased with increasing intervals between insemination and ovulation; within each $8 \mathrm{~h}$ interval, the variability between sows was large. When sows were inseminated for a second time, approximately $3 \mathrm{~h}$ after ovulation, the accessory sperm count was high, irrespective of the interval between first insemination and ovulation $(P>0.05)$. The variability in accessory sperm count between sows remained large after a second insemination. If the first insemination took place more than $8 \mathrm{~h}$ before ovulation, a second insemination after ovulation increased the accessory sperm count $(P<0.05)$. If the first insemination took place between 0 and $8 \mathrm{~h}$ before ovulation, a second insemination after ovulation did not increase the accessory sperm count $(P>0.10)$, but this comparison is based on only a few observations.

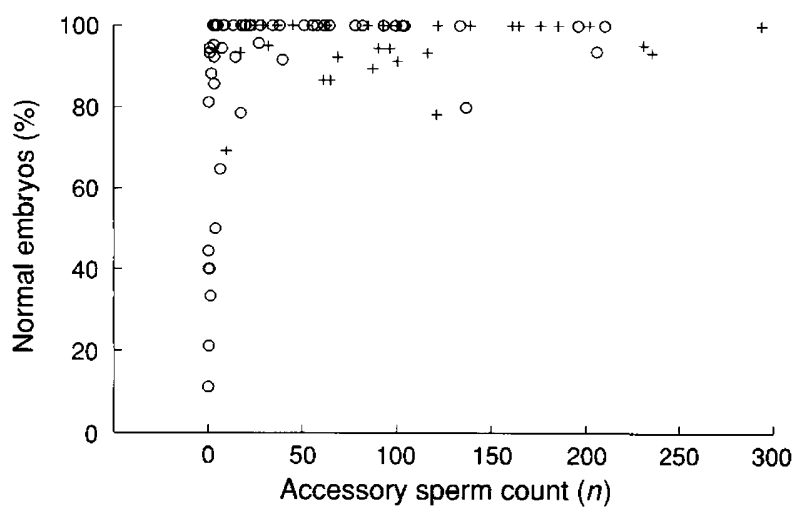

Fig. 1. The percentage of normal embryos per litter in relation to the average accessory sperm count of the normal embryos, in sows inseminated once $(\omega)$ or twice $(+)(n=86)$. Five sows with $0 \%$ normal embryos are not included; their average accessory sperm count varied between 0 and 0.5 .

The relationship between the average accessory sperm count of the normal embryos and the percentage of normal embryos per sow is shown (Fig. 1). The accessory sperm count of the embryos varied between 0 and almost 300 , and the percentage of normal embryos varied from approximately $20 \%$ to $100 \%$; a low accessory sperm count was associated with a low percentage of normal embryos in a litter. In addition, the five litters without normal embryos had a low accessory sperm count $(0-0.5)$. High accessory sperm counts were associated with a high percentage of normal embryos. The accessory sperm counts in the three sows inseminated between 0 and $8 \mathrm{~h}$ before ovulation and again after ovulation were 10,230 and 235; the corresponding percentage of normal embryos was 69,95 and 93, respectively.

\section{Discussion}

The present experiment was undertaken to study the effects of a second insemination after ovulation on fertilization Downloaded from Bioscientifica.com at 04/26/2023 01:58:55AM 
results and embryonic development. The number of sperm cells captured in the zona pellucida around fertilization (the accessory sperm cells) may serve as a measure for the number of fertile sperm cells at the site of fertilization (Baker et al., 1968; Hunter, 1984; Waberski et al., 1994; Soede et al., 1995). A second insemination after ovulation significantly increased the accessory sperm count if the first insemination took place more than $8 \mathrm{~h}$ before ovulation. So, apparently, the second insemination resulted in more fertile sperm cells at the site of fertilization. However, despite the higher number of accessory sperm cells, the sows that were inseminated for a second time after ovulation showed good fertilization results (percentage of normal embryos), irrespective of the timing of first insemination relative to ovulation. Furthermore, there was a positive relationship between the accessory sperm count of the normal embryos and the percentage of normal embryos; no reduction in percentage of normal embryos was seen with high numbers of accessory spermatozoa. We conclude that a second insemination within the first hours after ovulation does not lead to a reduction in normal fertilization.

We therefore suggest that polyspermic fertilization is not a major cause of embryonic losses under normal artificial insemination conditions. Polyspermic fertilization normally is assessed in the first hours after fertilization by counting the number of sperm cells or the number of pronuclei in the cytoplasm of the oocyte. Polyspermic embryos are said to degenerate early in development, but may seem normal up to the four- to eight-cell stage (Hunter, 1967b). No assessment has been made of the timing of degeneration of polyspermic embryos; however, it was assumed that (expanded) blastocysts at $120 \mathrm{~h}$ after ovulation were viable, normal, embryos that did not result from abnormal (polyspermic) fertilization. A second insemination in the first hours after ovulation resulted in higher accessory sperm counts, but not in reduced embryo survival at day 5 of pregnancy. Estimates of polyspermic fertilization have previously been made within the first hours after fertilization, often under unnatural conditions (progesterone injections, Day and Polge, 1968; oviductal insemination, Hunter, 1973; hCG injection, Hunter, 1967a) and in these experiments, the incidence of polyspermic fertilization has not been related to embryo survival. Even polyspermic fertilization at the end of the fertile lifespan of oocytes (Hunter, 1967b) may not occur frequently under natural conditions; reduced fertilization in sows inseminated after ovulation or long before ovulation is due to lack of fertilization and not to degenerating embryos (Soede et al., 1995). When sows were inseminated more than once during oestrus, the oocytes become fertilized by the sperm cells already present at the time of ovulation and not by the sperm cells inseminated after ovulation. Therefore, such oocytes are fertilized before they reach the end of their fertile life.

Sows inseminated only once showed a reduction in fertilization results when this insemination took place more than $24 \mathrm{~h}$ before ovulation. This is consistent with previous results (Waberski et al., 1994; Soede et al., 1995). Apparently, when insemination takes place too early relative to ovulation, too few sperm cells are present to ensure good fertilization. This is also shown by the reduction in accessory sperm cells of the normal embryos which is also consistent with previous results (Soede et al., 1995).

In contrast to previous research (Waberski et al., 1994; Soede et al, 1995), good fertilization results were found in sows inseminated after ovulation even when this was the second insemination. No relationship between oocyte age and fertilization rate was apparent. The good fertilization results in sows inseminated after ovulation may be related to differences in the fertile lifespan of the oocytes between (groups of) sows. However, no such effects on fertile lifespan of oocytes are known.

Sows inseminated for a second time after ovulation showed a longer duration of standing heat after ovulation $(P<0.01)$. Effects of mating and insemination on the timing of ovulation have been reported (reviewed by Soede, 1993), but in the present experiment, the second insemination took place after ovulation and the time of ovulation relative to the onset of oestrus was similar for the two groups of sows. As reported previously large differences were found in the duration of oestrus of sows in a herd (Willemse and Boender, 1967; Weitze et al., 1994; Soede et al., 1995) but the causes of this variability are poorly understood.

In conclusion, a second insemination in the first hours after ovulation positively affected normal fertilization, as is apparent from the high percentage of normal embryos and the positive relationship between the accesssory sperm count and the percentage of normal embryos. It is suggested that polyspermic fertilization is not of major importance for in vivo fertilization results.

The authors gratefully acknowledge the financial support of the Dutch Association of Dutch Artificial Insemination Centres for pigs and the assistance of B. Muller, A. Ammerlaan and S. Talsma.

\section{References}

Baker RD, Dziuk PJ and Norton HW (1968) Effect of volume of semen, number of sperm and drugs on transport of sperm in artificially inseminated gilts Journal of Animal Science $2788-93$

Day BN and Polge C (1968) Effects of progesterone on fertilization and egg transport in the pig Journal of Reproduction and Fertility $17227-230$

Hunter RHF (1967a) Effect of aging eggs on embryonic survival in pigs Journal of Animal Science 26945

Hunter RHF (1967b) The effects of delayed insemination on fertilization and early cleavage in the pig Journal of Reproduction and Fertility 13 $133-147$

Hunter RHF (1973) Polyspermic fertilization in pigs after tubal deposition of excessive numbers of spermatozoa Joumal of Experimental Zoology 183 57-64

Hunter RHF (1984) Pre-ovulatory arrest and peri-ovulatory redistribution of competent spermatozoa in the isthmus of the pig oviduct Journal of Reproduction and Fertility $\mathbf{7 2}$ 203-211

Hunter RHF (1994) Causes for failure of fertilization in domestic species. In Embryonic Mortality in Domestic Species pp 1-22 Eds MT Zavy and RD Geisert. CRC Press, Inc, Boca Raton

Hunter RHF and Dziuk PJ (1968) Sperm penetration of pig eggs in relation to the timing of ovulation and insemination Journal of Reproduction and Fertility 15 199-208

SASISTAT (1990) Users's Guide, SAS Institute, Cary, NC

Snedecor GW and Cochran WG (1989) Statistical Methods (8th edn), lowa State University Press, Ames, IA

Downloaded from Bioscientifica.com at 04/26/2023 01:58:55AM 
Soede NM (1993) Boar stimuli around insemination affect reproductive processes in sows. A review Animal Reproduction Science 32 107-125

Soede NM and Kemp B (1993) In synchronized pigs, the duration of ovulation is not affected by insemination and is not a determinant for early embryonic diversity Theriogenology 39 1043-1053

Soede NM, Noordhuizen JPTM and Kemp B (1992) The duration of ovulation in pigs, studied by transrectal ultrasonography, is not related to early embryonic diversity Theriogenology 38 653-666

Soede NM, Wetzels CCH, Zondag W, de Koning MAI and Kemp B (1995) Effects of time of insemination relative to ovulation, as determined by ultrasonog- raphy, on fertilization rate and accessory sperm count in sows Journal of Reproduction and Fertility 104 99-106

Waberski D, Weitze KF, Gleumes T, Schwarz M, Willmen T and Petzoldt R (1994) Effect of time of insemination relative to ovulation on fertility with liquid and frozen boar semen Theriogenology 42 831-840

Weitze KF, Wagner-Rietschel H, Waberski D, Richter L and Krieter J (1994) The onset of heat after weaning, heat duration, and ovulation as major factors in Al timing in sows Reproduction in Domestic Animals $29433-443$

Willemse AH and Boender J (1967) The relation between the time of insemination and fertility in gilts Tijdschrift Diergeneeskunde 92 18-34 